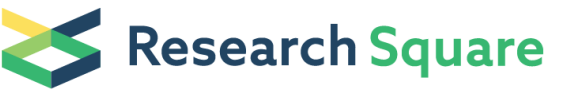

\section{Safety and Feasibility of Autologous Adipose-derived Stromal Vascular Fraction in the Treatment of Keloids: a Phase One Randomised Controlled Pilot Trial}

\section{Ronald Mbiine ( $\nabla$ mbiineron@gmail.com )}

Makerere University College of Health Sciences https://orcid.org/0000-0003-2403-1656

\section{Anthony Kayiira}

Lifesure fertility and gynaecology center

\section{Misaki Wayengera}

Makerere University CHS: Makerere University College of Health Sciences

lan Munabi

Makerere University CHS: Makerere University College of Health Sciences

\section{Noah Kiwanuka}

Makerere University CHS: Makerere University College of Health Sciences

\section{Rose Alenyo}

Makerere University CHS: Makerere University College of Health Sciences

\section{Edris Wamala Kalanzi}

Kirruddu National Referral hospital, Kampala

\section{Haruna Muwonge}

Makerere University CHS: Makerere University College of Health Sciences

\section{Cephas Nakanwagi}

Mulago Hospital: Mulago National Referral Hospital

\section{Moses Joloba}

Makerere University CHS: Makerere University College of Health Sciences

\section{Moses Galukande}

Makerere University CHS: Makerere University College of Health Sciences

\section{Research}

Keywords: Stromal vascular Fraction, Adipose stem cells, Keloids, scars, Low middle-income countries

Posted Date: September 30th, 2021

DOl: https://doi.org/10.21203/rs.3.rs-940210/v1

License: (9) (i) This work is licensed under a Creative Commons Attribution 4.0 International License. Read Full License 


\section{Abstract}

Autologous adipose-derived stromal vascular fraction (SVF) is described as a therapeutic alternative in keloid treatment. However, most conclusions are based on observational with the majority conducted in high-income countries and yet the highest-burden of keloids is in Low-and middle-income countries (LMICs). In order to explore the therapeutic benefits of SVF in keloids, the safety and feasibility of their use in LMICs need to be evaluated.

Methods: In this phase 1 randomized controlled pilot clinical trial conducted in the Plastic Surgery Unit of Kirruddu National Referral Hospital Kampala, 8 patients were assigned 1:1 ratio into either SVF or Triamcinolone Acetonide (TAC) arms. In the SVF arm, a median (IQR) number of stromal cell infiltration of $2.7 \times 10^{6}\left(11 \times 10^{6}\right)$ was administered while the controls received $10 \mathrm{mg} / \mathrm{ml} \mathrm{TAC}$ in a ratio of 1:1 TAC into keloid volume. Primary end-points were adverse events development based on the Common Terminology Criteria for Adverse Events (CTCAE) v5.0 tool and Feasibility assessment based on $\geq 70 \%$ recruitment feasibility and $\geq 80 \%$ interventional feasibility rates.

Results: Participant mean age was $27.9( \pm 6.5)$ years with a female predilection of $5(63 \%)$. Overall, no adverse events were reported in the SVF arm while an ulceration in a single patient in the TAC arm which was a grade II adverse event was reported. Recruitment feasibility of $80 \%$ as well as interventional feasibility with $100 \%$ completion were reported.

Conclusion: Based on our findings, autologous adipose-derived stromal vascular fraction is feasible and safe for the treatment of keloids.

Trial registration: ClinicalTrials.gov, NCT04553159. Registered $17^{\text {th }}$ September 2020. Link: https://clinicaltrials.gov/ct2/show/NCT04553159

\section{Background:}

Keloids are one of the commonest benign skin disorders[1] occurring mostly in individuals with coloured skin especially among Africans with an estimated prevalence of up to $16 \%[1,2]$. To date, there is no cure for the treatment of these keloids as all existing therapies have varied treatment response and invariably result in recurrence[3, 4].

Intralesional infiltration with the corticosteroid Triamcinolone Acetonide (TAC) is the recommended and most widely used non-surgical therapy either as a single drug or in combination with other treatments for small to medium keloids $[5,6]$. Despite the wide use of TAC, failure rates which are described either as recurrence or lack of response remain high[6, 7].

Because of these associated high failure rates in existing therapies, newer therapies such as adipose-derived stromal vascular fraction (SVF) have been explored. Studies on SVF and stem cells have shown that keloid growth can successfully be inhibited[8] demonstrating immense therapeutic potential in scar and keloid treatment $[8,9]$. These cells have been described to exert their therapeutic effects through paracrine based 
signalling that modulates excess inflammatory processes [10] as well as suppression of keloid fibroblast proliferation gene expression[11, 12].

Several studies have demonstrated both laboratory and clinical based response in keloid regression or inhibition of growth[12,13]. Despite this growing evidence of effectiveness of the adipose-derived stem cells in scar healing, the majority of studies have a low level of evidence with paucity of well-organized clinical trials to compare the efficacy of the SVF to the existing therapies. Without designed randomized controlled clinical trials, it's difficult to objectively determine the benefits of the SVF therapy in scar management and this subsequently deters future potential utilisation as standard therapy.

Utilization of Adipose-derived stromal vascular fraction is highly technical and demanding and before conducting a clinical trial, it's important that a pilot study is conducted.

In this study, we assessed the feasibility of conducting a clinical trial using stromal vascular fraction in keloid treatment. Secondly, we evaluated the safety of using the SVF in comparison to standard Triamcinolone Acetonide( TAC).

The findings of this pilot study will be used to develop a phase II clinical trial that will evaluate the efficacy of using stromal vascular fraction in the treatment of keloids.

\section{Materials And Methods:}

\section{Trial design:}

This was a parallel group single centre randomised controlled pilot trial with ratio of 1:1 conducted at the Plastic surgical unit of Kirruddu National Referral hospital in Kampala, Uganda from the months of March to July 2021. The trial was approved by the "The AIDS Support Organization (TASO) Research Ethics Committee (TASOREC/060/19-UG-REC-009) and the Kirruddu National Referral Hospital Research Ethics Committee and was also registered in the ClinicalTrials.gov under the registration number NCT04553159. The trial reporting followed the CONSORT Extended checklist for pilot clinical trials[14] and TIDier guidelines[15].

\section{Participants and eligibility criteria:}

Participants who met the eligibility criteria were consecutively selected out of patients seeking care for keloid treatment at the clinic.

Patients were eligible if they were aged between 18 to 65 years and had a single keloid of equal or less than $4 \mathrm{~cm}^{3}$ as these are treated non-surgically and hence qualified for non-surgical intervention. Patients who were underweight (BMI less than 18.5) were excluded as they had insufficient fat pads to enable liposuction. Patients who had three months prior received intralesional therapy or cutaneous radiotherapy were excluded as the effect of previous therapy couldn't be ruled out. Patients with active systemic illnesses demonstrated by symptoms of fever, cough, gastroenteritis, or laboratory diagnosis would be excluded. Similarly, patients with bleeding disorders or anti-coagulation therapy were to be excluded. 
Included participants were provided with complete oral and written information ahead of their consent. Informed consent was then obtained following a 48 hours period in which participants were allowed to consult relatives or other stakeholders.

\section{Intervention:}

Once participants were included in the study, baseline characteristics were obtained following which they were randomized and allocated into either treatment arms as described below.

\section{The Autologous Adipose-Derived Stromal Vascular Fraction (SVF) group}

Participants in this arm received a single dose intra-lesional infiltration of the autologous adipose-derived stromal vascular fraction. The dosage depended on the total number of viable SVF cells in the cellular suspension and was expressed as total viable cells per $\mathrm{ml}$ of suspension. Final cell suspension volume was constituted in a 1:1 ratio of the keloid volume with $1 \mathrm{ml}$ of cell suspension per cubic centimetre of keloid tissue.

In order to obtain the stromal vascular fraction, the steps described below were followed.

Harvesting adipose tissue:

Tumescence liposuction was performed aseptically on the outer thigh following the infiltration of $300 \mathrm{ml}$ of tumescent solution (constituted as $20 \mathrm{ml}$ of $2 \%$ Lignocaine, $1 \mathrm{ml}$ of $1: 1000$ epinephrine, $12.5 \mathrm{ml}$ of $8.4 \%$ Sodium Bicarbonate in 1 litre of normal saline). Through a 3-4mm skin incision, liposuction into a $10 \mathrm{ml}$ Leuer lock syringe attached to a $3 \mathrm{~mm}$ Coleman liposuction cannula was performed with 100 to $150 \mathrm{ml}$ of lipoaspirate was collected into $50 \mathrm{ml}$ sterile falcon centrifuge tubes. The liposuction cannula entry incision was closed with a 6/0 Monocryl absorbable suture and a pressure bandage placed.

Standard operation theatre aseptic protocols were followed and the procedures were conducted in a dedicated plastic surgery operation theatre by qualified plastic surgeons.

Extraction of stromal vascular fraction:

The harvested lipo-aspirate see Fig. 2a, was processed aseptically from a designated sterile unit in the operating theatre. The Lipoaspirate was washed using 1X Dulbecco's Phosphate Buffered Saline-PBS (Lonza, Walkersville, MD USA) and then subsequently enzymatically digested using $0.075 \%$ Type $1 \mathrm{~A}$ Collagenase (MERCK Millipore, USA). Enzyme stop media comprising of 10\% Foetal Bovine Serum-FBS (SIGMA St. Louis, MO USA) in Dulbecco's Modified Eagle Medium (DMEM)-High glucose (SIGMA St. Louis, MO USA) was used to neutralize the enzymatic process (See Fig. 2b). The Stromal vascular fraction pellet (Fig. 2c) was was subsequently incubated in $10 \mathrm{ml}$ of Red Cell Lysis Buffer (SIGMA St. Louis, MO, USA) at room temperature for 10 minutes and later washed in 1XPBS. Through a 100 $\mu$ m nylon cell strainer (BD Falcon, NJ, USA) the mixture was filtered to remove any unwanted tissue debris. Centrifugation at $1200 \mathrm{~g}$ resulted in the stromal vascular fraction (SVF) pellet which was then resuspended into 1.5mls of Ringer's Lactate solution.

To determine the cell count and viability, to $10 \mu$ l of the cell suspension was added an equal volume of $0.4 \%$ Trypan blue(SIGMA St. Louis, MO USA) and then mounted into a Neubauer counting chamber as per Strober's guideline[16]. Cells were counted at X40 Objective magnification as shown in Fig. 3. 
Total nucleated cells per $10 \mu \mathrm{l}$ were used to determine the final cell dosing while viability was determined using the Trypan blue exclusion test[16]. The total number of viable cells on the Neubauer counting chamber were used to calculate the total number of cells in the $1.5 \mathrm{ml}$ suspension factoring in the two times dilution factor during the trypan blue staining.

The stromal vascular fraction dosing was constituted by diluting the SVF suspension to a 1:1 ratio of SVF volume to keloid volume. Hence for a $4 \mathrm{~cm}^{3}$ keloid, the $1.5 \mathrm{ml}$ of original SVF suspension was constituted to make $4 \mathrm{ml}$ by addition of 1 XPhosphate Buffered Saline (PBS). The final infiltration cellular dosing calculation per millilitre was computed and medication placed into hypodermic syringes ready for infiltration.

\section{The Triamcinolone Acetonide (TAC) group:}

For this arm, one ampoule of Triamcinolone acetonide (TAC) containing 40mg in $1 \mathrm{ml}$ was used for each patient. To each $\mathrm{ml}$ of Triamcinolone was added $1 \mathrm{ml}$ of $2 \%$ lidocaine and $2 \mathrm{mls}$ of Water for injection to constitute $4 \mathrm{ml}$ of TAC suspension with a concentration of $10 \mathrm{mg}$ per $\mathrm{ml}$. The suspension was placed in hypodermic syringes for subsequent infiltration into the keloid tissue. For each patient, a maximum of $40 \mathrm{mg}$ of Triamcinolone could be infiltrated for the keloid under study.

The standard dosing for the triamcinolone for keloid volume as described by Rahban and Ganner[17]. Injection of the SVF and TAC into the keloid:

The selected keloid was prepped with $10 \%$ Povidone lodine and then appropriately draped.

Infiltration into the keloid depended on the keloid morphology, volume and shape.

Each keloid, where applicable was divided into four quadrants and the infiltration dose was equally divided into the four quadrants. Infiltration volume of $0.1 \mathrm{ml}$ per cubic millimetre or $1 \mathrm{ml}$ for every cubic centimetre was targeted. Hence each keloid received which-ever therapy at a dosing of $1 \mathrm{ml}$ for every cubic centimetre.

Where the keloid scar was found to be very hard and difficult to infiltrate, 'needling' was performed. 'Needling' is when a 22-gauge needle is used to create a mesh/network of interconnecting tunnels $2 \mathrm{~mm}$ apart into the keloid. Following this, infiltration of the treatment was instituted into the created tunnels.

\section{General trial procedure:}

Patients that were included and consented to the trial underwent standard pre-operative care including informed consent for surgery. The research assistants enrolled the participants, obtained baseline characteristics, and then randomized and allocated them into either treatment arm. The intervention was administered by a qualified surgeon who had previously been trained on the standards and practices of the procedures. Following the procedure, post-procedural analgesics were provided to participants based on the hospital guidelines for day-care surgery. At follow-up, patients were reassessed clinically at the plastic surgical clinic. The reviews were scheduled at one week and one month while a final follow-up at the end of three months upon which the participants exited the study. The project principal investigator undertook the follow-up reviews. Participants were provided with a transport refund during the follow-up visits.

\section{Outcome:}


The primary outcome variables were safety and feasibility of using autologous adipose derived stromal vascular fraction in the treatment of keloids in comparison to Triamcinolone Acetanoide.

Safety.

Adverse events were defined based on the Common Terminology Criteria for Adverse Events (CTCAE) v5.0 tool as any un-favourable and un-intended symptom, sign or disease associated with the use of a medical treatment or procedure that may or may-not be directly an intended result of the procedure. These adverse events experienced by the participants were documented based on the CTCAE v5.0 [18] and these were reported on a running daily basis for the entire study period. Specific assessments for adverse events development were conducted on day 0 (immediate post procedure), Day 1, day seven, one and three months. The participants were asked to spontaneously report any adverse events to the study principal investigator through a phone call at any time during the follow-up period and the principal investigator would then followup with the necessary intervention.

Adverse events were graded as seen in Table 1 and the adverse event grade at each assessment time was recorded.

Table 1

Common Terminology Criteria for Adverse Events (CTCAE) v5.0 tool

\begin{tabular}{|c|c|c|}
\hline Grade & & \\
\hline $\begin{array}{l}\text { Grade } \\
1\end{array}$ & Mild & Mild symptoms, no intervention required. \\
\hline $\begin{array}{l}\text { Grade } \\
2\end{array}$ & Moderate & Minimal or local non-invasive intervention needed. \\
\hline $\begin{array}{l}\text { Grade } \\
3\end{array}$ & $\begin{array}{l}\text { Severe or medically } \\
\text { significant }\end{array}$ & $\begin{array}{l}\text { Severe but not immediately life threatening. Requires } \\
\text { hospitalization, disabling }\end{array}$ \\
\hline $\begin{array}{l}\text { Grade } \\
4\end{array}$ & $\begin{array}{l}\text { Life threatening } \\
\text { consequences }\end{array}$ & Urgent intervention indicated \\
\hline $\begin{array}{l}\text { Grade } \\
5\end{array}$ & Death & \\
\hline
\end{tabular}

\section{Feasibility.}

The criteria for feasibility were based on four parameters that had to be met for the procedure to be considered feasible. which all had to be feasible for the procedures to be classified as feasible.

- Recruitment feasibility: This refers to the enrolment and acceptability to participate among those that were found to be eligible. Obtaining consent in $70 \%$ of the first 10 respondents reached out to was described as feasible for recruitment. For those that declined, reasons for the decline were sought out.

- Intervention feasibility: As a day-care procedure: 
- Procedure time: The total procedure time in hours was determined. Durations of equal or less than 5 hours were described as feasible.

- Procedure completion rates and general anaesthesia conversion:

The procedure was intended to be conducted under local anaesthesia with optional opioid analgesia addition. Completion, as described above without the need for conversion to general anaesthesia or procedural abandonment, was described as feasible.

- Suitability of outcome measurements:

Keloid thickness measurement: The keloid height/thickness was determined in millimetres using a highfrequency Ultrasound (Healcerion SONON portable ultrasound model $300 \mathrm{~L}$ ). This ultrasound scan device has a capacity of length measurement with up to two decimal point accuracy. Suitability was described as the interobserver ability to consistently reproduce three ultrasound thickness measurements at the same site with a variation of $\leq \pm 0.03$.

The feasibility of assessing the primary outcome measures of the main trial of Patients and Observer Scar Assessment Score (POSAS), Keloid volume calculation were also assessed.

Completion rates and challenges in assessing each of these were evaluated.

- Follow up feasibility:

- Assessment for co-intervention:

Participant utilization of any other treatment during the follow-up period, the timing of use, and the reason were determined.

- Appropriateness of timing for next intervention:

The study follow-up was set up for three months however the appropriateness of this follow-up was evaluated to establish the optimal timing before subsequent follow-up therapy. This was based on the duration of symptom remission or symptom-free duration.

Secondary outcomes:

Clinical outcomes were the mean change in the Patient and Observer Scar Assessment Scores (POSAS) from baseline to one month and three months.

Monitoring treatment fidelity:

Because it was the first time this kind of study was being conducted, it was important that treatment fidelity was monitored. Specifically, fidelity adherence checklists were developed and each key step in the study implementation was compared to the described protocol to evaluate the degree of deviation. Deviations from the protocol were identified and the reasons reported. For each procedural step, the investigator was asked to rate how compliant they were in keeping to the trial protocols. Secondly, standardization training of the participants and research assistants was performed to ensure consistency in trial procedures 


\section{Sample size estimation:}

This was a phase one study intended to explore the safety, feasibility and refine the trial process and not establish effect. Therefore, hypothesis testing to establish a sample size was not necessary. This was based on the recommendations of Arain[19].

In order to establish the sample size, we used the formular by Lackey et al[20] where they propose that pilot study the sample size comprise of $10 \%$ of the main trial size. Based on this recommendation, a pilot sample size of 8 participants which is $10 \%$ of the main clinical trial sample size was established with 4 participants allocated in each arm.

\section{Randomization and Allocation concealment:}

Randomization was performed using STATA command ralloc by a statistician who was not directly involved in the study. Block randomization using block size 2 was used to allocate patients following a 1:1 ratio.

Sequentially numbered opaque envelopes were used to conceal the allocation sequences and these were prepared by the same statistician that generated the randomization. The envelopes were stapled and handed to the recruitment nurse who only interfaced with the patients during the allocation of treatment the day of the procedure and not interacted with the enrolling research assistant.

At the time of allocation into the different study arms, the recruiting nurse would detach the sequential envelope to identify the allocation and subsequently keep the envelope.

\section{Blinding:}

The nature of the study procedure made it impossible to blind the patients and the surgeons as liposuction instantly revealed which arm the patient was allocated. The Outcome assessors on the other hand who followed up patients for review were blinded as they didn't know what intervention the participants had received.

\section{Statistical methods:}

Data analysis for the participant demographics, baseline characteristics, safety, feasibility, took on a descriptive approach with all data being exported and analysed in STATA 15.0.

Continuous data was reported as means $( \pm S D)$ while categorical data was reported as proportions with their percentages.

Categorical data analysis was performed for the first primary end-point of safety. Proportions with the percentages of the different Common Terminology Criteria for Adverse Events (CTCAE) v5.0 grades were obtained. Broadly two categories of "adverse event" and "no adverse events" were analysed and compared between the two treatment arms using chi square tests.

For the second primary endpoint of feasibility, variables were categorized into feasible or not feasible and the proportions determined. Comparison between the two treatment arms was performed using chi square tests. 
For the secondary outcomes, efficacy endpoints were merely exploratory and therefore analytical assessments were not performed. These were continuous variables and were reported as means with standard deviations. We evaluated for the presence of mean differences in the two treatment arms at one week, one month and three months and baseline.

\section{Patient \& Public involvement:}

Patients and participants were not be involved in the development of the research question, choice of outcome measures, design of the trial, recruitment of participants and conduct of the trial. Results of the trial were disseminated to the study participants through direct consultation.

\section{Results:}

\section{Characteristics of the study participants:}

Eight participants were recruited during the months of March and April 2021 and were followed up for three months with the last follow-up taking place in July 2021.

Their mean age was 27.9( \pm 6.5$)$ years while five of the participants were female. The rest of the demographics are presented in Table 2. Despite the randomization, all the participants that were allocated into the intervention arm were female while one female was allocated into the control arm. The mean BMI was 27.9 ( \pm 6.0) with the BMI generally higher among the intervention arm. The mean keloid duration was $4.4( \pm 5.5)$ years and all these participants hadn't received any therapy in the last three months.

Table 2

Baseline characteristics of study participants

\begin{tabular}{|lllllll|}
\hline Participant & Age & Sex & BMI & $\begin{array}{l}\text { Location of } \\
\text { keloid }\end{array}$ & $\begin{array}{l}\text { Duration of } \\
\text { keloid(years })\end{array}$ & $\begin{array}{l}\text { Treatment } \\
\text { intervention }\end{array}$ \\
\hline 001 & 24 & Male & 23.3 & Sternal & 1 & TAC \\
\hline 002 & 26 & Female & 32.4 & Sternal & 1 & SVF \\
003 & 24 & Female & $35.3^{\prime}$ & $\begin{array}{l}\text { Sub- } \\
\text { mandibular }\end{array}$ & 18 & SVF \\
004 & 39 & Female & 35.9 & Epigastric & 2 & SVF \\
005 & 25 & Male & 19.8 & Sternal & 6 & TAC \\
006 & 20 & Female & 21.6 & Earlobe & 5 & SVF \\
\hline 007 & 25 & Male & 23.9 & $\begin{array}{l}\text { Lateral } \\
\text { infrapatellar }\end{array}$ & 2 & TAC \\
008 & 36 & Female & 31.2 & Breast & 1 & TAC \\
\hline Mean & $27.9( \pm$ & NA & $27.9( \pm$ & NA & $4.4( \pm 5.5)$ & NA \\
\hline *NA-Not applicable, TAC-Triamcinolone Acetonide, SVF-Stromal Vascular Fraction & \\
\hline
\end{tabular}


In the SVF arm, participants selectively preferred the liposuction point to be the outer thigh out of three options of the abdominal, inner thigh, and outer thigh. The mean infiltrated volume of tumescence fluid was 387.5( \pm $114) \mathrm{ml}$ with a mean lipoaspirate volume of $137.5( \pm 37.7) \mathrm{ml}$.

The total cell counts among the participants were found to be skewed. Particularly one participant had an outlier value. Specifically, she was a lactating mother 7 months post-partum. Because this data wasn't normally distributed, we used medians with their interquartile ranges (IQR) instead of mean with the standard deviations. Following the processing, the mean total number of viable stromal cells in the entire lipoaspirate was estimated to be $9.9 \times 10^{6}\left( \pm 13.8 \times 10^{6}\right)$ cells with mean dosing of $3.2 \times 10^{6}\left( \pm 4.6 \times 10^{6}\right) \mathrm{cells} / \mathrm{ml}$ of infiltrating suspension. The median total number of stromal cells was $2.7 \times 10^{6}$ cells with an interquartile range of $11 \times 10^{6}$ cells. Overall cellular viability was reported at $94 \%$. For details see Table 3 .

Table 3

Characteristics of participants in SVF arm

\begin{tabular}{|llllllll|}
\hline No. & $\begin{array}{l}\text { Tumescence } \\
\text { fluid } \\
\text { infiltrated }\end{array}$ & $\begin{array}{l}\text { Lipoaspirate } \\
\text { volume }\end{array}$ & $\begin{array}{l}\text { Processed } \\
\text { lipoaspirate }\end{array}$ & $\begin{array}{l}\text { Total } \\
\text { viable cell } \\
\text { count } \\
\text { harvested }\end{array}$ & $\begin{array}{l}\text { Infiltration } \\
\text { volume } \\
(\mathbf{m l})\end{array}$ & $\begin{array}{l}\text { Infiltration } \\
\text { dose } \\
\text { cells/ml }\end{array}$ & $\begin{array}{l}\text { Cellular } \\
\text { viability }\end{array}$ \\
\hline 002 & 500 & 200 & 110 & $4.5 \times 10^{6}$ & 5 & $9 \times 10^{5}$ & 98 \\
\hline 004 & 500 & 130 & 70 & $33.6 \times 10^{6}$ & 3 & $11.2 \times 10^{6}$ & 98 \\
\hline 004 & 300 & 120 & 57 & $6 \times 10^{5}$ & 3 & $2 \times 10^{5}$ & 85 \\
\hline 007 & 250 & 100 & 52 & $8.4 \times 10^{5}$ & 1.5 & $5.6 \times 10^{5}$ & 95 \\
\hline Mean & 387.5 & 137.5 & 72.3 & $9.9 \times 10^{6}$ & 3.25 & $3.2 \times 10^{6}$ & 94 \\
$( \pm$ SD $)$ & $( \pm 114)$ & $( \pm 37.7)$ & $( \pm 22.8)$ & $( \pm$ & $( \pm 1.1)$ & $( \pm$ & $( \pm 5.3)$ \\
\hline Median & 400 & 125 & 63.5 & $2.7 \times 10^{6}$ & 3 & $7.3 \times 10^{5}$ & 96.5 \\
$($ IQR $)$ & $(212.5)$ & $(32.5)$ & $(24.3)$ & $\left(11 \times 10^{6}\right)$ & $(0.75)$ & $\left(3 \times 10^{6}\right)$ & $(5.5)$ \\
\hline
\end{tabular}

\section{Comparison of safety profile:}

On the day of intervention, there were no adverse events that were reported and all patients were subsequently discharged as had been intended. There were still no adverse events at the 24 hours follow-up. Overall, no serious adverse events were recorded. One participant in the Triamcinolone group reported the development of an ulcer at the infiltration site which developed on day five following the intervention. This required administration of oral antibiotics and analgesics and a topical antibacterial cream but no surgical intervention or hospitalization. Subsequently, the ulcer healed by the second week of follow-up. Among the SVF group, there were no reported adverse events in the entire follow-up period. 


\section{Feasibility of Adipose derived stromal vascular fraction:}

Overall, both treatments were feasible with no comparable differences.

\section{Recruitment feasibility.}

Among the first 8 eligible participants that were reached out to, two declined to participate in the study after they had received information about the clinical trial. This prompted us to reach out to the next two eligible participants who accepted to participate in the study. Based on this, overall, recruitment feasibility stood at $80 \%$. The reason for decline for one was the unwillingness to have another site away from the keloid operated upon while the second one strictly wanted to have surgical excision.

\section{Intervention feasibility.}

Duration of procedure: Averagely the procedure time for Triamcinolone was 30 minutes to one hour while that of the SVF took a mean time of 5 hours. All interventions were successfully conducted as day-care procedures and no patient required hospitalization.

Procedure completion rates: All intended procedures had a completion rate of $100 \%$. This means that no procedure was abandoned once it had been started. Secondly, there was no conversion to general anaesthesia as all patients tolerated the procedure.

In the SVF arm, one patient needed supplemental opioid analgesia and was given IV Fentanyl 50 mcg which sufficiently controlled the break-through pain during the liposuction process.

\section{Suitability of outcome measurements:}

Keloid thickness: Two independent radiologists performed cutaneous ultrasound to determine the keloid scar thickness. The inter-observer variability was within the stipulated margin of \pm 0.03 .

Surface area estimation using photography when compared to surface area mapping using tracing paper was found more un-reliable with variability in establishing focal length and angles. Surface area mapping using tracing paper proved a more reliable measurement estimate.

Follow up feasibility.

Co-intervention:

Among all patients, all but one didn't seek additional therapy during the first two months of therapy. The patient that developed the ulcer had to seek extra therapy and she received a topical antibacterial cream.

Secondary outcome:

All participants Patient and Observer Scar Assessment Scores (POSAS) improved(reduced) by a mean of $12.5( \pm 7.2)$ and $7.6( \pm 3.1)$ at one month and three months respectively when compared to baseline. The onemonth mean difference in the improvement of POSAS scores between SVF and TAC was 14.8( \pm 8.6) and 10.3( \pm 4.6$)$ respectively. At three months the mean difference in POSAS scores when compared to baseline 
was 7.8( \pm 3.3$)$ and 7.5 $( \pm 2.9)$ in the SVF and TAC arms respectively. All patients in all arms reported resolution of itching and noted scar softening.

Treatment fidelity:

To ensure adherence to treatment fidelity, all study staff were trained on the strict adherence to the research protocol. In all participants in both arms, adherence to the protocol was followed.

\section{Discussion:}

To date, there a few clinical trials comparing autologous adipose derived stromal vascular fraction to other keloid therapies whilst the majority of existing studies being observational[13, 21, 22]. Secondly, most published studies are in high income countries casting uncertainty on feasibility of conducting similar trials in Low-and Middle-Income countries where the greatest burden of keloids is found[23, 24]. To the best of our knowledge, no clinical trial has been published particularly in sub-Saharan Africa exploring this therapy.

This trial therefore provides critical information on feasibility of conducting this study in a resource limited setting in addition to describing its safety while also comparing it to the widely used therapy of Triamcinolone acetonide.

With the broader goal of conducting a phase II clinical trial to evaluate the efficacy of SVF in keloid treatment, a preliminary phase I trial was required to provide preliminary feasibility and safety data.

Feasibility of SVF:

In order to appropriately determine the feasibility, key steps of the study were identified and evaluated. This being a new therapy, the willingness of participants to enrol was unknown and yet this would fundamentally determine the success of the trial. Therefore, recruitment feasibility was assessed. With recruitment feasibility at $80 \%$, the pilot scored well above the minimum feasibility score of $70 \%$. Among the two participants that declined, one had earlier been scheduled for surgical excision and had missed surgery and therefore opting for the earlier treatment plan. The second patient expressed her scepticism about being involved in an entirely new therapy that had not been practiced in the country earlier. This recruitment feasibility rate is comparable to studies conducted elsewhere SVF use is described as feasible[23, 25].

For interventional feasibility testing, key technical aspects of the procedures were assessed including completion rates. All treatment arms passed the set interventional feasibility test. Specifically, for SVF, five hours duration enabled the procedure to be performed as a day care procedure. This was found comparable to other studies with treatment durations of 4 hours[26] and three hours[25]. In one study by Karina, a shorter time of 2-3 hours excluded the infiltration and observation time. The fact that no patients required conversion of anaesthesia to general and the completion rates of $100 \%$ clearly demonstrated the feasibility of the trial procedure especially as a day care therapy. Other centres similarly conduct SVF as a day care procedure with the use of Tumescence liposuction[25, 26].

Safety:

Page 12/19 
For the safety of the procedure, overall patients who received the SVF intervention did not report any adverse events during the entire study period. These findings are in keeping with reports described elsewhere[25, 27, 28]. According to one systematic review by Gentile, there were no particular adverse events associated with SVF treatment in scar tissues[29] besides the pain that comes with the procedure. Overall, SVF therapy for intralesional scar treatment is safe. On the contrary, the Triamcinolone arm registered one case of grade II adverse event. Ulceration following infiltration of TAC has been described and is a well-known side effect[30]. The development of this adverse event highlights the limitation of TAC as the most commonly use keloid treatment. This forms a justification for the need for alternative therapy.

In both treatment arms, there were improvements in the POSAS scores at both one month and three months. The difference was most marked at one month with the decline in scar improvement possibly explainable by the waning treatment effect. All patients in both arms described symptom resolution of itching in addition to softening of the scars. However, despite the promising improvement in POSAS scores, this study was neither intended nor powered to draw any such conclusions on efficacy as this is the primary objective of the anticipated phase II trial.

Strengths and limitations:

One strength of this trial is that patients were randomized to minimize bias. Secondly the real-time evaluation of treatment fidelity ensured adherence to developed protocols. The description of the SVF arm as feasible is a strength of this study as it forms the foundation for conducting a phase II clinical trial. This is the first randomized clinical trial evaluating stromal vascular fraction in sub-Saharan Africa and will play a role in advancing the practice on the continent.

Some limitations in our study included the allocation of one gender into the intervention arm despite the block randomization. This was due to the small sample size as well as predominantly female attendance in the plastic surgical clinic. This may be due to the cosmetically disfiguring nature associated with keloids. With this gender skew, SVF characteristics among the males weren't evaluated. This however will guide the randomization of the phase II trial with specific incorporation of stratification for sex during the randomization process.

\section{Conclusion:}

Based on our findings, autologous adipose derived stromal vascular fraction is feasible and safe for the treatment of keloids. The trial demonstrates that SVF therapy can be safely performed as a day care procedure. Although not designed to assess efficacy, the trial describes promising improvement in the POSAS scores and symptom relief for all participants during the follow-up time.

\section{RECOMMENDATIONS:}

Based on this pilot trial, we recommend that a phase II randomized controlled trial comparing efficacy in SVF and TAC is conducted.

\section{Abbreviations:}


CTCAE: Common Terminology Criteria for Adverse Events

POSAS: Patient and Observer Scar Assessment Score

SVF: Stromal vascular Fraction

TAC: Triamcinolone Acetonide

\section{Declarations:}

\section{Ethical approval and consent to participate:}

The trial was approved by the "The AIDS Support Organization (TASO) Research Ethics Committee (TASOREC/060/19-UG-REC-009) and the Kirruddu National Referral Hospital Research Ethics Committee.

The clinical trial was registered under ClinicalTrials.gov. Registration number NCT04553159. Registered on $17^{\text {th }}$ September 2020. Link: https://clinicaltrials.gov/ct2/show/NCT04553159

\section{Consent for Publication:}

Not Applicable

\section{Availability of datasets:}

The datasets used and/or analysed during the current study are available from the corresponding author on reasonable request

\section{Competing interests:}

The authors declare that there are no competing interests.

\section{Funding/Support:}

Research reported in this publication was supported by the Fogarty International Centre of the National Institutes of Health, U.S. Department of State's Office of the U.S. Global AIDS Coordinator and Health Diplomacy (S/GAC), and President's Emergency Plan for AIDS Relief (PEPFAR) under Award Number 1R25TW011213. The content is solely the responsibility of the authors and does not necessarily represent the official views of the National Institutes of Health."

Additional funding was obtained from the Makerere University Research Innovation Fund (MakRIF) grant registration: MAK/DVCFA/113/20.

The funding sources had no role in the design and implementation of the study.

\section{Author's contributions:}

RM conceptualized, designed and conducted the study, he directly participated in the writing, editing and critical review of this manuscript. 
MW, IM, NK, HM, MM and MG read and reviewed manuscript as well as supervised the implementation of the project.

RA and EWK supervised and participated in the liposuction process to obtain the SVF. They supervised the clinical implementation of the project.

$\mathrm{CN}$ and AK reviewed and edited the manuscript. All authors read and approved the manuscript.

\section{ACKNOWLEDGEMENTS:}

We wish to acknowledge the staff of the department of Plastic surgery at Kirruddu National Referral hospital Kampala for the commitment during the implementation of the study. We also wish to acknowledge the Department of Physiology at Makerere University College of Health Sciences for the provision of laboratory space and key equipment needed during this study.

\section{References:}

1. McGinty S SW: Keloid. In: In: StatPearls [Internet]. vol. Treasure Island (FL); 2020.

2. Rockwell WB, Cohen IK, Ehrlich HP: Keloids and hypertrophic scars: a comprehensive review. Plastic and reconstructive surgery 1989, 84(5):827-837.

3. Betarbet U, Blalock TW: Keloids: A Review of Etiology, Prevention, and Treatment. The Journal of clinical and aesthetic dermatology 2020, 13(2):33-43.

4. Ekstein SF, Wyles SP, Moran SL, Meves A: Keloids: a review of therapeutic management. Int J Dermatol 2021, 60(6):661-671.

5. Mustoe TA, Cooter RD, Gold MH, Hobbs FD, Ramelet AA, Shakespeare PG, Stella M, Téot L, Wood FM, Ziegler UE: International clinical recommendations on scar management. Plastic and reconstructive surgery 2002, 110(2):560-571.

6. Jacobs $\mathrm{C}$, Wilmink J: Combined versus single treatment regimens for keloid therapy using serial intralesional corticosteroid injections, surgical excision, silicone- and/or cryotherapy. JPRAS open 2021, 29:157-166.

7. Ojeh N, Bharatha A, Gaur U, Forde AL: Keloids: Current and emerging therapies. Scars Burn Heal 2020, 6:2059513120940499-2059513120940499.

8. Wang X, Ma Y, Gao Z, Yang J: Human adipose-derived stem cells inhibit bioactivity of keloid fibroblasts. Stem cell research \& therapy 2018, 9(1):40-40.

9. Silva VZ, Albacete AN, Horácio GS, Andrade GA, Procópio LD, Coltro PS, Farina JAJ: Evidences of autologous fat grafting for the treatment of keloids and hypertrophic scars. Revista da Associacao Medica Brasileira (1992) 2016, 62(9):862-866.

10. Borovikova AA, Ziegler ME, Banyard DA, Wirth GA, Paydar KZ, Evans GRD, Widgerow AD: Adipose-Derived Tissue in the Treatment of Dermal Fibrosis: Antifibrotic Effects of Adipose-Derived Stem Cells. Annals of plastic surgery 2018, 80(3):297-307.

11. Xie F, Teng L, Xu J, Lu J, Zhang C, Yang L, Ma X, Zhao M: Adipose-derived mesenchymal stem cells inhibit cell proliferation and migration and suppress extracellular matrix synthesis in hypertrophic-scar and 
keloid fibroblasts. Exp Ther Med 2021, 21(2):139.

12. Liu J, Ren J, Su L, Cheng S, Zhou J, Ye X, Dong Y, Sun S, Qi F, Liu Z et al: Human adipose tissue-derived stem cells inhibit the activity of keloid fibroblasts and fibrosis in a keloid model by paracrine signaling. Burns : journal of the International Society for Burn Injuries 2018, 44(2):370-385.

13. Mattei A, Magalon J, Bertrand B, Grimaud F, Revis J, Velier M, Veran J, Dessi P, Sabatier F, Giovanni A: Autologous adipose-derived stromal vascular fraction and scarred vocal folds: first clinical case report. Stem cell research \& therapy 2018, 9(1):202-202.

14. Eldridge SM, Chan CL, Campbell MJ, Bond CM, Hopewell S, Thabane L, Lancaster GA: CONSORT 2010 statement: extension to randomised pilot and feasibility trials. BMJ (Clinical research ed) 2016, 355:i5239.

15. Hoffmann TC, Glasziou PP, Boutron I, Milne R, Perera R, Moher D, Altman DG, Barbour V, Macdonald H, Johnston $\mathrm{M}$ et al: Better reporting of interventions: template for intervention description and replication (TIDieR) checklist and guide. BMJ : British Medical Journal 2014, 348:g1687.

16. Strober W: Trypan Blue Exclusion Test of Cell Viability. Curr Protoc Immunol 2015, 111:A3.B.1-A3.B.3.

17. Rahban SR, Garner WL: Fibroproliferative scars. Clinics in plastic surgery 2003, 30(1):77-89.

18. Freites-Martinez A, Santana N, Arias-Santiago S, Viera A: Using the Common Terminology Criteria for Adverse Events (CTCAE - Version 5.0) to Evaluate the Severity of Adverse Events of Anticancer Therapies. Actas dermo-sifiliograficas 2021, 112(1):90-92.

19. Arain M, Campbell MJ, Cooper CL, Lancaster GA: What is a pilot or feasibility study? A review of current practice and editorial policy. BMC medical research methodology 2010, 10:67.

20. Anita L. Wingate NRL: : The Pilot Study: One Key to Research Success. In: Advanced Design in Nursing Research. 2 edn. Thousand Oaks Thousand Oaks, California: SAGE Publications, Inc.; 1998: 375.

21. Negenborn VL, Groen JW, Smit JM, Niessen FB, Mullender MG: The Use of Autologous Fat Grafting for Treatment of Scar Tissue and Scar-Related Conditions: A Systematic Review. Plastic and reconstructive surgery 2016, 137(1):31e-43e.

22. Use of the Stromal Vascular Fraction in Intermediate-Deep Acute Burns: A Case With Its Own Control. In., vol. 39; 2018: 846-849.

23. Mattei A, Bertrand B, Jouve E, Blaise T, Philandrianos C, Grimaud F, Giraudo L, Aboudou H, Dumoulin C, Arnaud $L$ et al: Feasibility of First Injection of Autologous Adipose Tissue-Derived Stromal Vascular Fraction in Human Scarred Vocal Folds: A Nonrandomized Controlled Trial. JAMA Otolaryngology-Head \& Neck Surgery 2020, 146(4):355-363.

24. Zhou BR, Zhang T, Bin Jameel AA, Xu Y, Xu Y, Guo SL, Wang Y, Permatasari F, Luo D: The efficacy of conditioned media of adipose-derived stem cells combined with ablative carbon dioxide fractional resurfacing for atrophic acne scars and skin rejuvenation. In: Journal of cosmetic and laser therapy : official publication of the European Society for Laser Dermatology. 3 edn. England; 2016: 138-148.

25. Karina K, Rosliana I, Rosadi I, Schwartz R, Sobariah S, Afıni I, Widyastuti T, Remelia M, Wahyuningsih KA, Pawitan JA: Safety of Technique and Procedure of Stromal Vascular Fraction Therapy: From Liposuction to Cell Administration. Scientifica 2020, 2020:2863624.

26. Park Y, Lee YJ, Koh JH, Lee J, Min H-K, Kim MY, Kim KJ, Lee SJ, Rhie JW, Kim W-U et al: Clinical Efficacy and Safety of Injection of Stromal Vascular Fraction Derived from Autologous Adipose Tissues in 
Systemic Sclerosis Patients with Hand Disability: A Proof-Of-Concept Trial. Journal of clinical medicine 2020, 9(9):3023.

27. Aronowitz JA, Lockhart RA, Hakakian CS, Hicok KC: Clinical Safety of Stromal Vascular Fraction Separation at the Point of Care. Annals of plastic surgery 2015, 75(6):666-671.

28. Mazur S, Zołocińska A, Siennicka K, Janik-Kosacka K, Chrapusta A, Pojda Z: Safety of adipose-derived cell (stromal vascular fraction - SVF) augmentation for surgical breast reconstruction in cancer patients. Advances in clinical and experimental medicine : official organ Wroclaw Medical University 2018, 27(8):1085-1090.

29. Gentile P, Sterodimas A, Calabrese C, Garcovich S: Systematic review: Advances of fat tissue engineering as bioactive scaffold, bioactive material, and source for adipose-derived mesenchymal stem cells in wound and scar treatment. Stem Cell Research \& Therapy 2021, 12(1):318.

30. SCHETMAN D, HAMBRICK GW, JR., WILSON CE: Cutaneous Changes Following Local Injection of Triamcinolone. Archives of Dermatology 1963, 88(6):820-828.

\section{Figures}

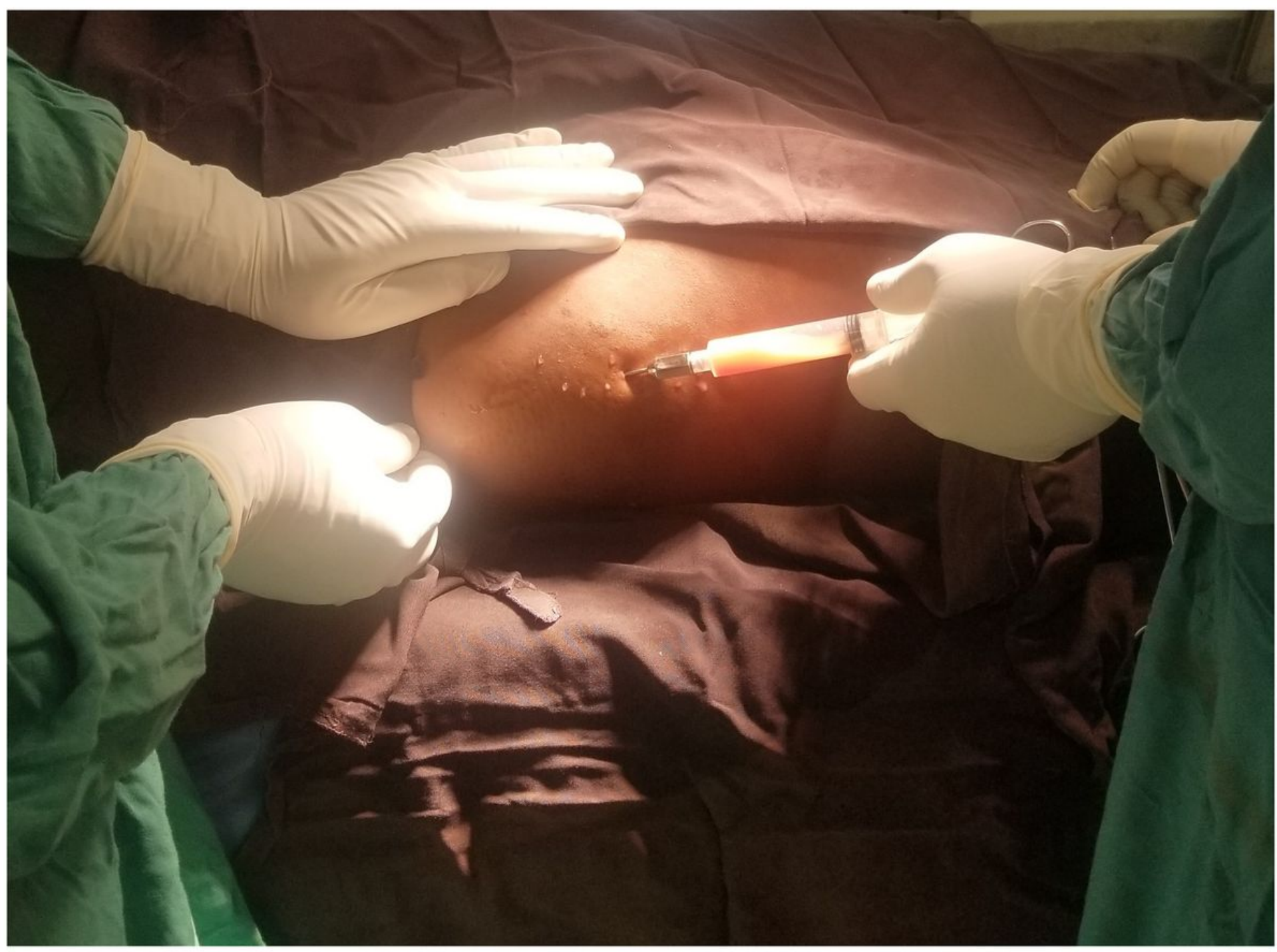


Figure 1

Liposuction process being aseptically performed.
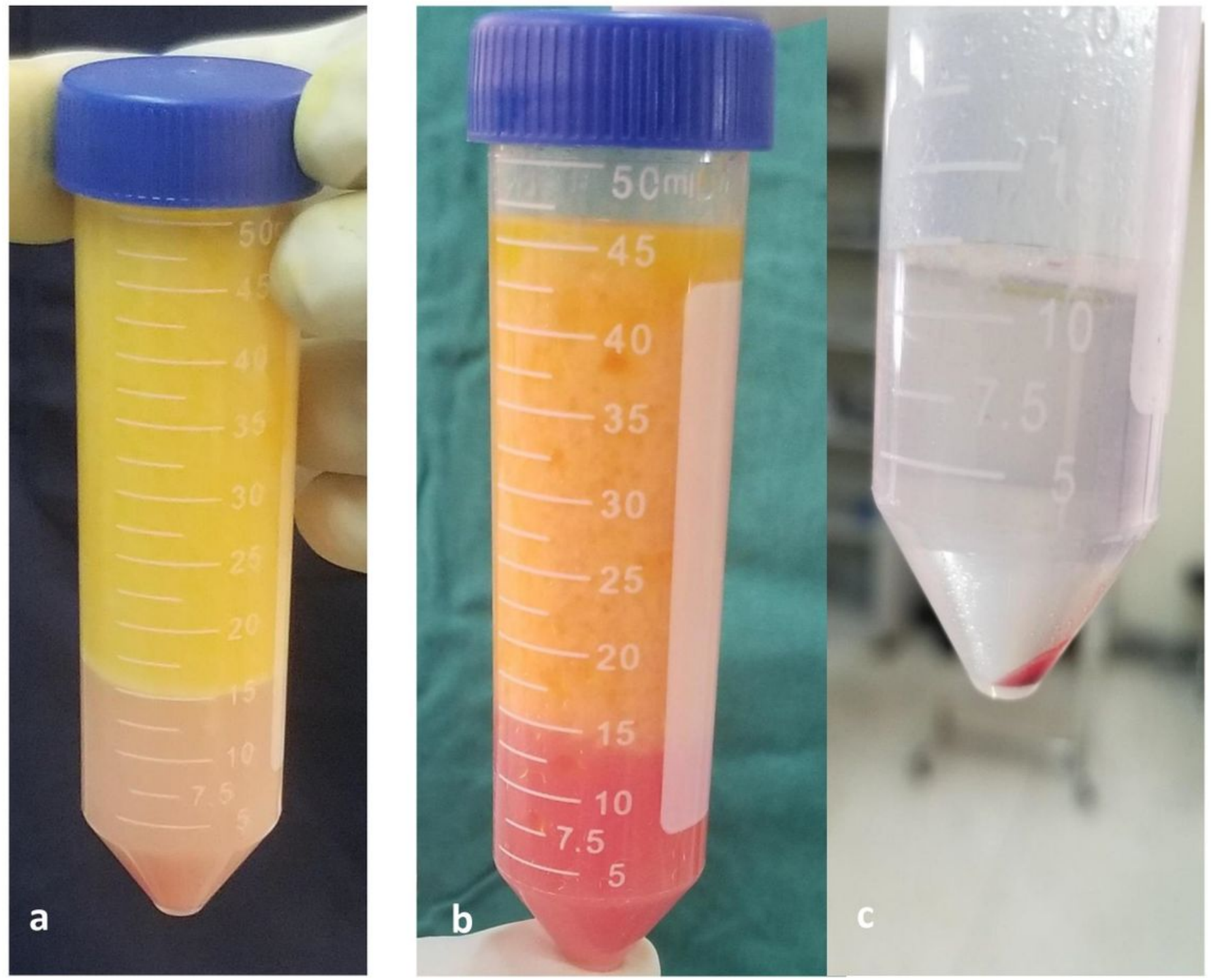

\section{Figure 2}

Lipoaspirate processing to obtain the stromal vascular fraction. 


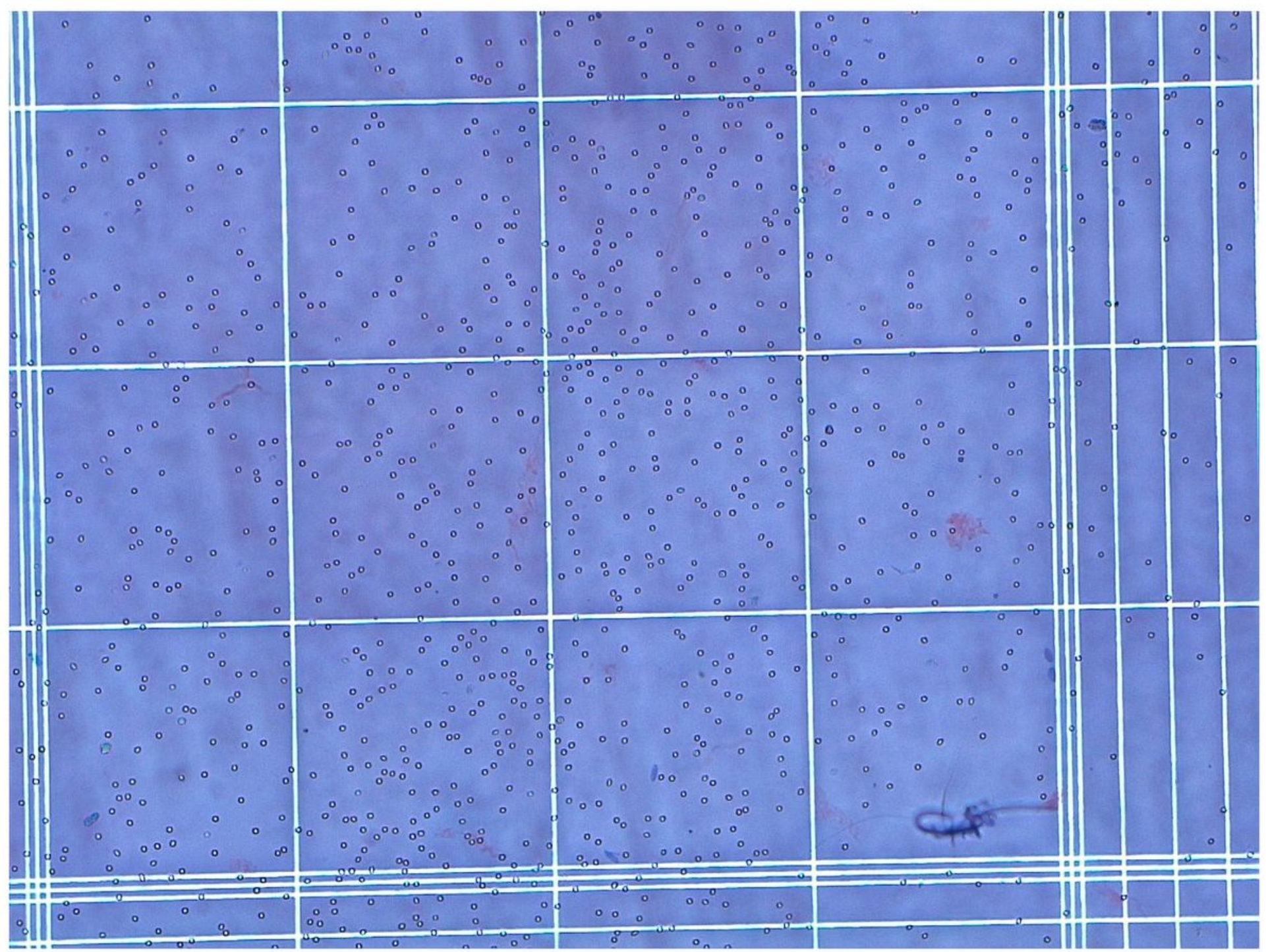

Figure 3

Stromal cells following staining using Trypan blue ready for cell counting.

\section{Supplementary Files}

This is a list of supplementary files associated with this preprint. Click to download.

- CONSORTextensionforPilotandFeasibilityTrials.doc 